\title{
El hombre nuevo y la religión. Misterio Bufo de V. Maiakovski e Iván en el Paraíso de A. Lunacharski
}

Recibido: 17/11/2020. Aceptado: 22/6/2021.

\begin{abstract}
Resumen
A partir de una discusión acerca de las diferentes concepciones filosóficas, políticas y literarias que atañen a la noción de hombre nuevo, concepto que tuvo un desarrollo particular en la literatura rusa y en las consignas e ideales políticos de la Revolución Rusa, el presente artículo se propone discutir la manera en que dicho concepto se forja y modula en dos textos literarios de comienzos de la revolución. Emprenderemos para ello el análisis de Misterio Bufo, de V. Maiakovski e Iván en el Paraíso, de A. Lunacharski. Si bien ambos textos apelan a la religión para construir por contraste un nuevo ideal secular del hombre, sus poéticas y técnicas literarias producen modelos del hombre nuevo no solo muy diferentes entre sí, sino reveladores de las tensiones internas entre los agentes revolucionarios respecto del curso que deseaban para la revolución.
\end{abstract}

Palabras clave: hombre nuevo; religión; Revolución Rusa; Maiakovski; Lunacharski.

The New Man and Religion. V. Mayakovsky's Mystery-Bouffe and A. Lunacharsky's Ivan in Paradise

\begin{abstract}
Starting from a discussion about the different philosophical, political and literary conceptions regarding the notions of a new man, concept that had a particular development in the russian literature and in the slogans and political ideals of the Russian Revolution, the present article aims to discuss the way in which the aforementioned concept is forged and given shape in two literary texts from the beginning of the revolution. In order to do so, we will analyze V. Mayakovsky's Mystery-Bouffe and A. Lunacharsky's Ivan in Paradise. Although both texts resort to religion to build by contrast a new secular ideal of man, their poetics and literary techniques produce not only very different models of the new man, but models that reveal the internal tensions among the revolutionary agents in respect of the path they wished for the revolution.
\end{abstract}


Andréi Siniavski sostiene en su libro La civilización soviética que la idea de un "hombre nuevo' fue enunciada originalmente no por la revolución, sino por la religión" (Siniavski, 1990: 94). Se refiere a que el cristianismo pediría al creyente que "se purifique del pecado y, con la ayuda divina, se convierta en un hombre nuevo" (94). Acto seguido, afirma que "los 'hombres nuevos' creados por la revolución pertenecen también al tipo religioso: fe fanática en el comunismo, idea de sacrificio, rechazo de la ventaja personal y renuncia de sí mismo" (94). Pero por efecto de alguna "extraña modificación del sentido moral" (94), los hombres nuevos soviéticos, según Siniavski, a diferencia del "revolucionario ruso del tipo antiguo", quien "siempre consideró que la violencia sangrienta [...] era un pecado", predican el terror y lo traducen "en oleada de asesinatos" (94-95).

Con la idealización tosca y la cristianización forzada del enigmático "revolucionario ruso de tipo antiguo", Siniavski forja por contraste la imagen del revolucionario comunista como un monstruo amoral. La yuxtaposición del hombre nuevo soviético con el hombre nuevo cristiano le permite al autor, al mismo tiempo, hacer del primero un tipo religioso. En un mundo (el de Siniavski) en el que nada escapa a lo religioso, el hombre nuevo queda en una posición de Anticristo: ¿de qué otra manera podemos pensar la antítesis del cristianismo en términos cristianos? Con menos rigor argumentativo que resentimiento, pero fiel a estas premisas, Siniavski construye el Estado soviético como Iglesia y a Stalin como pontífice.

Ahora bien, nuestra posición es fundamentalmente otra. No se puede comprender cabalmente la idea de hombre nuevo que surge en la revolución rusa si confundimos pensamiento religioso con pensamiento secular, si no distinguimos entre esencia y procedimiento o función. Ni los murciélagos son pájaros, ni las ballenas peces. Además, toda apropiación implica un devenir.

Sin embargo, antes de abordar la relación entre hombre nuevo y religión en Misterio bufo (1918 y 1920-21), de Vladímir Maiakovski e Iván en el Paraíso (1920), de Anatoli Lunacharski, es necesario hacer alguna reflexión sobre la posibilidad misma de un hombre nuevo. Hay una posición que la niega, que ve en el hombre una naturaleza estable y transhistórica. Esta constituye su identidad, e intentar cambiarla sería no solo inútil, también perjudicial. Dentro del propio marco revolucionario, Alexandr Chaiánov expresa esta posición esencialista. En Viaje de mi hermano Alexéi al país de la utopía campesina (1920), el anfitrión de Alexéi, "un canoso patriarca" encargado de contarle cómo funciona la Rusia campesina utópica del futuro, nos dice:

Nos cuidamos especialmente del estado, al que usamos solo cuando lo exige la necesidad. La experiencia política de muchos siglos, por desgracia, nos enseña que la naturaleza humana casi siempre sigue siendo la naturaleza humana, la suavización del carácter transcurre a la velocidad de los procesos geológicos (Chaiánov, 2011: cap. 11).

Tenemos aquí otra vez la referencia a la articulación entre hombre nuevo y política estatal, típica de los socialismos estatales de corte soviético. Chaiánov ve en el estado, creemos que con razón y en la línea clásica marxista, un factor coercitivo. Sin embargo, no le contrapone la posibilidad de un hombre nuevo libre. Antes bien, niega su posibilidad, quitándole así al Estado al menos uno de sus argumentos coercitivos. 
Frente a esta línea de pensamiento, hay toda una corriente filosófica, así como una práctica literaria, que piensa al hombre como algo abierto, mutable, maleable y, según el caso, perfectible.

Para Giorgio Agamben, lo humano se produce. En su libro sobre la relación entre lo humano y lo animal, el filósofo define el funcionamiento de las máquinas antropológicas antigua y moderna, como solo posible porque instituyen

en su centro una zona de indiferencia en la que debe producirse -como un missing link siempre faltante porque ya virtualmente presente- la articulación entre lo humano y lo animal. Como todo espacio de excepción, esta zona está en verdad perfectamente vacía (Agamben, 2006: 76).

La manera en que se llena el vacío (qué se excluye y qué se incluye) da la concepción variable que el hombre tiene de sí mismo a lo largo de la historia. Surge claramente de este razonamiento que cualquier definición del hombre es provisoria e ideológica. Al mismo tiempo, el hombre queda igualmente definido por su vacío. El vacío pasa a ser una negatividad que habría que afirmar frente a los intentos de llenarlo: desconfianza radical de cualquier ideología. Por otra parte, si bien Agamben se refiere más que nada a la producción de lo humano como distintivo de lo animal y lo inhumano, sus conclusiones pueden generalizarse sin problema a la cuestión que nos ocupa: el hombre nuevo en tanto contenido psicosocial particular correspondiente a determinadas circunstancias históricas. Si lo humano en general es algo abierto y producible, mucho más sus posibles tipologías.

Friedrich Nietzsche difiere de Agamben en algunos puntos. Con no menos desconfianza de la ideología, el pensador alemán afirma la vida, sin embargo, contra el nihilismo, contra la voluntad de la nada (¿el vacío?). Y si bien para Nietzsche la negación es constitutiva del hombre (Deleuze, 1998: 247), aun así nos exhorta al superhombre, cuya tarea es la creación de nuevos valores. Sería erróneo, por supuesto, equiparar al superhombre con el hombre nuevo soviético. Si bien el hombre nuevo está pensado también en términos de valores, el superhombre apunta más lejos, es "la especie superior de todo lo que es" (Deleuze, 1998: 247). Es decir, más un horizonte de pensamiento que un tipo social. Pero en última instancia, también el hombre, ya que Nietzsche afirma igualmente el devenir, el "escape" posible de uno mismo. El superhombre es, también, "lo desconocido [que el hombre] lleva consigo" (Deleuze, 1998: 247); es decir, el resultado del hombre mismo, porque, para decirlo con Nietzsche, el hombre no es "una meta, sino solo un camino, un episodio intermedio, un puente, una gran promesa" (Nietzsche, 1996: 97).

Frente a esta apertura teórica del hombre, la literatura rusa, sobre todo desde sus corrientes realistas, ha insistido históricamente en la posibilidad práctica de captar nuevos tipos psicosociales a través de los tipos literarios. Sus autores lo declaran abiertamente. Ya A. Pushkin quiere retratar en su Prisionero del Cáucaso los "rasgos característicos de la juventud del siglo XIX" (Pushkin, 2006: T.9, 52). Dostoievski y Turguéniev compiten por captar los tipos nuevos de su sociedad. Turguéniev capta al primer nihilista de su época en el personaje de Bazárov e introduce así, al mismo tiempo, en la sociedad el término nihilista; también le da nombre al tipo del hombre superfluo con su relato Diario de un hombre superfluo. Dostoievski se enorgullece de captar tipos por primera vez (passim en su obra). ${ }^{3}$ Chernishevski no solo retrata a los

2 En términos parecidos propone el Che Guevara a su hombre nuevo: "una conciencia en la que los valores adquieran categorías nuevas" (1978: 11).

3 Cf. López Arriazu (2019a), para una discusión sobre tipo literario y polifonía en Dostoievski. 
hombres nuevos de su generación, y les da ese nombre, describe, además, al hombre nuevo del futuro y a la mujer nueva, Vera Pávlovna.

Sobre este fondo histórico, filosófico y literario, del que se rescata la naturaleza cambiante del ser humano y la creencia en su perfectibilidad, hay que pensar el intento de forjar un hombre nuevo para una nueva sociedad en la Rusia revolucionaria. El intento registra en el plano discursivo un período de formación que se extiende entre 1919 y 1924, pero que mantiene su presencia hasta finales de la década del ' $30 .{ }^{4}$

Por otro lado, es notable el abundante uso literario de la imaginería religiosa ya sea para combatir la religión o para expresar un cambio social que trastoca todas las estructuras socioeconómicas, acelera el tiempo histórico, altera las nociones de futuro y se siente, por su radicalidad, de dimensiones sobrehumanas. Es una estrategia propia del comienzo de la revolución, a la que ya casi no se apela a partir de la década del '30. Además de Lunacharski y Maiakovski, hay que nombrar al menos a M. Gorki y A. Blok. Gorki ya en 1908, en su novela Confesión, propone el socialismo como una fe en el hombre, como la construcción de una religión sin dios, una postura que el joven Lunacharski comparte en su Religión y socialismo, también de 1908. Pero no todos los casos son iguales, se puede pensar que Blok intenta reconciliar revolución atea y religión otorgándole cierto misticismo al acto revolucionario, mirándolo no ya como un equivalente religioso en otro campo, sino a través de un prisma propiamente religioso. Su tema, como señala A. Murashov, es ante todo la desaparición del viejo mundo. Los "casi apóstoles de Los doce son solo una alusión simbólica al hombre nuevo que se dibuja entre los elementos triunfantes, entre el mundo viejo del ancien régime que se destruye" (Murashov, 2016). También fuera del ámbito literario está la exaltación científica de los biocosmistas y su búsqueda de la inmortalidad, quienes a veces abrevan en la "mística material" de N. Fiódorov, pero para que la ciencia tome la posta de las esperanzas del filósofo; 5 o el intento del Arzobispo Metropolitano A. Vvedenski, en un sentido opuesto, de pensar el propio ateísmo como una religión, con el fin de lograr cierta sintonía con los dirigentes ateos y así una nueva alianza entre Iglesia y Estado. ${ }^{6}$ Dentro de este campo discursivo en disputa, Maiakovski y Lunacharski están del lado de los que combaten abiertamente la religión, si bien con estrategias muy diferentes, como veremos.

En cuanto al auge y disminución de la imaginería religiosa, creemos que se explican por dos causas: porque era necesario primero y porque ya no lo era después. Basta pensar en la veintena de páginas del sermón del infierno, terrible y material, del Retrato de un artista adolescente (1916) de J. Joyce, para darse cuenta de la vigencia y fuerza que tenían en la sociedad occidental de la época los discursos religiosos. Las iglesias oficiales eran todavía aliadas poderosas de los Estados, la sociedad estaba atravesada por sus discursos. Era necesario tomarlos para discutirlos y desarmarlos, o aprovecharlos para reconducir un mensaje. El triunfo de la estrategia explica que ya casi no se recurriera a ella a partir de la década del treinta. No puede subestimarse el éxito de la empresa (en líneas generales, más allá de que, como toda acción de este tipo, se haya plasmado en gran cantidad de matices y posiciones incluso enfrentadas) si consideramos que somos hoy, en buena medida, los hombres nuevos, seculares, que se concibieron entonces. El proceso de secularización en Occidente es, por supuesto,

${ }_{4}$ Para un análisis sobre las variaciones del tema de una década a otra y la relación discursiva entre el hombre nuevo y el hombre viejo, cf. Murashov (2016).

5 La literatura no deja, sin embargo, de recoger estas ideas. Un ejemplo es el mismo Maiakovski. Cf. R. Jackobson (1977).

6 Cf. en Lunacharski (2012), el debate "Cristianismo o comunismo" del 20 de setiembre de 1925, entre Lunacharski y A. Vvedenski, uno de los líderes de la Iglesia Viva, considerado hereje por la Iglesia ortodoxa por su movimiento cismático de reforma. 
un proceso histórico que se remonta al Renacimiento. En el siglo XIX, Feuerbach, Marx y Nietzsche desbarrancan las concepciones deístas del XVIII y son la base sobre la que operarán las estrategias filosóficas de secularización de comienzos del siglo XX. Pero el período que nos ocupa es el que quizás le da un golpe final a la religión como discurso cotidiano y masivo para la discusión de los problemas sociales. No solo en literatura, tampoco en filosofía se encontrarán ya discursos que necesiten oponerse tan fuertemente a los religiosos.

Tanto Maiakovski como Lunacharski quieren derribar los discursos religiosos desde una posición revolucionaria, ambos los incluyen en sus piezas e incluso les dan, con diferencias, la forma teatral de los misterios medievales. Ambos quieren destronar a Dios y erigir al hombre. Pero lo hacen de maneras tan disímiles que las piezas son vehículos de contenidos incluso antitéticos. Ambos evidencian una lucha interna dentro del campo revolucionario, que se resolverá en favor de Lunacharski, si bien, justicia poética mediante, seguimos prefiriendo leer y poner en escena a Maiakovski.

En un debate del 27 de noviembre de 1920 en la Casa de la Imprenta, en el que participaron, entre otros, Víktor Shklovski y Vladímir Maiakovski como representantes del ala formalista-futurista, Platón Kérzhentsev, dirigente del Proletcult, y A. Lunacharski, se discutió la obra dramática Iván en el Paraíso, del propio Lunacharski. Todos estaban en contra de Lunacharski. Se discutía el tipo de literatura que le correspondería mejor a la revolución. Para el Proletcult, la obra de Lunacharski era demasiado filosófica y no combatía directamente la religión, la consideraban reaccionaria y buscaban que el partido prohibiera su publicación. Shklovski sostiene que "las piezas de Lunacharski son, en efecto, reaccionarias, pero reaccionarias desde el punto de vista teatral", pues "el arte siempre es futurista en tanto crea formas nuevas" (Kojnó, 1972). I. Kojnó, quien repone el debate, sostiene, para defender a Lunacharski de los proletcultistas, que Iván en el Paraíso debe relacionarse más con los misterios de Byron que con los medievales, porque "todo el interés de Lunacharski se concentra no en la acción externa, sino en el desarrollo de las ideas filosóficas" (Kojnó, 1972). En efecto, la pieza casi carece de acción. Es una disputa filosófica sobre el bien y el mal puesta en boca de los personajes. Remeda la actitud feuerbachiana, cuya filosofía se inicia en discusión abierta con la teología, al tiempo que parece querer poner en acto, como sostiene Kojnó, las palabras de Marx:

La crítica de la religión desemboca en la doctrina de que el hombre es la esencia suprema para el hombre y, por consiguiente, en el imperativo categórico de echar por tierra todas las relaciones en que el hombre sea un ser humillado, sojuzgado, abandonado y despreciable (Kojnó, 1972).

Lo que para Kojnó salva la pieza de las críticas proletcultistas, la hunde a los ojos de Shklovski y de Maiakovski.

Misterio bufo opera de otro modo. Cruzado con el mejor humor de las bufonadas, el misterio se hace grotesco. Se evita así cualquier riesgo de diálogo filosófico abstracto. Además, la pieza es pura acción y movimiento ya desde antes de empezar, aún en el papel. No solo cambia su forma entre la primera versión y la segunda, sino que las didascalias que la presentan se lo encargan a las puestas futuras. Maiakovski dice: "conservando el camino (la forma), volví a cambiar parte del paisaje (el contenido)", y pide: "cambien el contenido... háganlo contemporáneo, del hoy, del minuto" (Maiakovski, 1988: 452). La forma es el camino que va de la revolución al comunismo; el contenido es el paisaje, los rostros que pueden cambiar, pero también los obstáculos a superar. Se puede estar en 
el camino sin caminar, ir para quedarse, como en Esperando a Godot, pero esa no es la ruta de Maiakovski. El camino es vertiginoso. Empieza en los hielos polares del Norte, sigue por barco, no cree en el ancla del Ararat, se hunde en el infierno y asciende al cielo para bajar a la Tierra Prometida... y ponerse a trabajar. Todo se mueve, fluye y se transforma: los personajes y el paisaje, el agua que todo lo inunda, el futuro que viaja en barco y el pasado que ya no existe, hasta el punto fijo del sol:

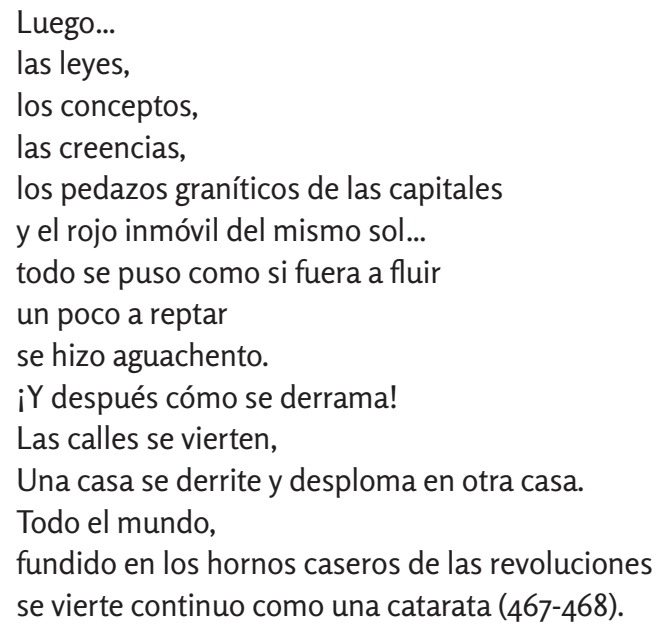

El escenario, ese lugar que por ser un no-lugar puede ser cualquier lugar, deja de ser la caja donde el avance siempre es lateral hacia bambalinas: se rompe la cuarta pared, los personajes circulan por la sala y el público sube al final al escenario. Porque, en el canto de cierre de La Internacional, público y actores se transforman. Ahora son todos actores de la revolución: el cierre mismo se transforma en apertura.

Sabemos que Lunacharski apoyó con entusiasmo la primera puesta de Misterio bufo, pero en el mismo artículo critica a los futuristas: "son la continuación de cierto hartazgo estético del viejo mundo, tienen debilidad por las bromas, por las excentricidades, por todo lo raro e infrecuente" (Lunacharski, 1918). Iván en el Paraíso fue escrita solo dos años después, casi junto con la segunda versión de Misterio bufo, como si fuera su propuesta alternativa. ¿Pero qué nos da Lunacharski a cambio del futurismo, que él concibe como pasado? Un pasado que quiere camuflarse de futuro.

No solo opone Lunacharski estatismo a dinamismo, sino Razón a devenir. La pregunta de Iván en la quinta escena: “¡cómo [Dios] permitió el mal?" (Lunacharski, 2020: 42) es el centro formal y simbólico de la pieza. Además de suspender la acción dramática, pues Iván quiere "entender con la razón" (42), la pregunta deja caer todo el andamiaje racional en las redes de la escolástica. Es decir, Lunacharski discute teología en el lenguaje de la teología. No hay diferencia entre la "Verdad" a la que sirve Egori, en términos de concepción de la verdad, y la verdad de Lunacharki. La pieza despliega el juego medieval de la realidad y la apariencia: "Es evidente que aquí hay un misterio, un saber que supera nuestra razón" (35), dice Iván haciendo del suspenso un Misterio. Al igual que con Maiakovski, el paraíso de Lunacharski no es tal, existe la pena y la angustia, pero en Maiakovski se afirma la tierra, en Lunacharski todo conduce a la Verdad que ha de revelarse al final de la pieza.

Lo mismo sucede en el plano del verosímil, no ya del desarrollo dialéctico de las ideas. El comienzo de la pieza crea el verosímil para su lectura. Lo primero que se discute es la realidad incorpórea del cuerpo celestial, lo que nos lleva a aceptar la lógica de ese mundo y medirla de acuerdo a su contenido, más que por su crítica. Personajes y dramaturgo se toman de la mano. El pope Avraami mantiene en el paraíso su cuerpo 
avejentado pues al envejecer "valoraron su bondad bajo la cáscara" (31). Lunacharski adhiere al rechazo asceta del cuerpo humano al hacer que a Iván, desnudo pues la ropa no viaja al cielo, lo cubra una túnica celestial. ¡Qué diferencia con la inundación sin lluvia de Maiakovski! Ya desde el comienzo nos aclara que todo eso es "alegórico", puro procedimiento, que estamos en realidad hablando de otra cosa.

La discusión de Lunacharski tiene entonces una orientación teológica; Maiakovski es una línea de fuga de la teología. La diferencia se ve con claridad en cómo ambos dialogan con la Leyenda del Gran Inquisidor de Dostoievski. ${ }^{8}$ Notemos aquí que Lunacharski no sólo remeda el diálogo del Gran Inquisidor con Cristo, sino que retoma el problema en los términos en que lo plantea Dostoievski: el sentido del Mal. “¿Cómo Dios permitió el mal?" es la pregunta que se hace Iván Karamázov. El gran inquisidor responde: para que el hombre tenga la libertad de elegir a Cristo. Exactamente la misma respuesta de San Pablo en Iván. Pero Iván, en el afán de Lunacharski de desenmascarar por la razón el concepto teológico de libertad, simplemente invierte los términos. No son libres quienes eligen a Dios, sino quienes lo rechazaron y están en el infierno: "Ellos son la esencia de la libertad, por su libertad los descartaron, fueron rechazados y castigados por ser libres... ¡Cruel tirano!" (46). La antítesis de una mala dialéctica. Como diría Bazárov, "un lugar común opuesto" (Turguéniev, 1994: 114).

Maiakovski no discute. Ignora el tema del mal. Cuando en el cielo los ángeles reciban a los recién llegados con leche y pan de nubes, sentiremos un eco de Dostoievski con su oposición del pan terrenal y el pan celestial, pero apenas eso, un sonido que retrocede y se desvanece ante la fuerza material del deseo. Porque el cielo no es un buen lugar para vivir, no hay siquiera sillas para comer. La libertad también aparece, pero desplazada. La palabra figura solo cuatro veces. La primera, irónicamente, en boca del intelectual en la frase hecha de "Libertad, igualdad, fraternidad", y la cuarta, como contrapunto, en otra frase también hecha, en el verso de La Internacional, "hoy está libre el mundo". Las otras dos veces no están en boca de los hombres, sino de las cosas. Primero una de las máquinas exclama “iLibre soy de ahora en más!” (542) y luego las comidas nos cuentan que "También el pan es de ahora en más libre y dulce" (543). La libertad no se busca, se encuentra en el trabajo y pertenece al presente-futuro: "de ahora en más", "de ahora en más", "hoy".

No obstante, podría pensarse que ambas piezas llegan a lugares idénticos. En la disputa simbólica contra la religión para quitar a Dios del centro y poner en su lugar al hombre, ${ }^{10}$ Maiakovski calca en ruso la máxima de Feuerbach Homo homini deus est ("El hombre es dios para el hombre"): "Мы сами себе и Христос и спасител!" ("Nosotros somos Cristo y el salvador para nosotros", 516). Lunacharski, por su parte, hace exclamar a Iván, tras la abdicación de Dios, que "Dios es la meta de la lucha, / El nuevo dios luminoso. / La divina meta... la creación: / Volver a erigir un palacio" (58). Se trata del "hombre-dios", del Palacio de cristal de Vera Pávlovna.

Pero tanto los finales en sí como los resultados conceptuales no podrían ser más diferentes. Esto ocurre porque durante el transcurso de las piezas Maiakovski logra operar una verdadera transvaloración de los valores cristianos, mientras que Lunacharski apenas los resignifica.

8 Para un análisis más detallado de la literatura utópica y distópica, cf. López Arriazu, E. (2020).

9 Así define el concepto Bazárov, el protagonista de Padres e hijos de Turguéniev: “decir, por ejemplo, que la ilustración es útil es un lugar común; y decir que la ilustración es perjudicial es un lugar común opuesto. Es algo más a la moda, pero en esencia es lo mismo" (114).

10 Algo relativamente fácil de hacer, si se piensa que tanto la religión monoteísta judeo-cristiana (que aquí nos concierne) como toda la cultura occidental que se forjó en interacción con ella son eminentemente ya de por sí antropocéntricas.

11 El personaje que representa la mujer nueva de N. Chernishevski en ¿Qué hacer? 
Los dos elementos que operan fuertemente la transvaloración en Maiakovski son el trabajo y la igualdad radical entre el hombre y las cosas. Ya desde el primer acto los impuros declaran que "nuestro trabajo es nuestra patria" (465). Luego, en el acto quinto, el triunfo sobre la Ruina será por medio del trabajo: “iTodos a trabajar! / ¡Trabajar hasta el desmayo!" (530). Esto cambia la formulación de los valores centrales. Como señala M. Ivanova en su excelente análisis de la obra: "la polémica con la concepción ortodoxa del paraíso, el derrocamiento del ideal cristiano de la santidad llevan a una total revisión de la noción tradicional del bien" (Ivanova, 2007: 142). El trabajo deja de ser la maldición de Dios. En el "paraíso" del hombre futuro, en sus "cielos terrenales", seguirá habiendo trabajo, pero a la medida del hombre, uno "que no encallece la mano" (498). El futuro de trabajo libre en igualdad con las máquinas se opone en Maiakovski al infierno, también terrenal, donde la explotación se da por las máquinas y la cultura. El trabajo es, además, como también señala Ivanova, un concepto dinámico, que se opone por su naturaleza a la naturaleza estática del paraíso celestial. Hacer el bien, en términos cristianos, es algo que termina, que se hace "hasta el paraíso" (Ivanova, 2007: 142-143). Por el contrario, el trabajo dinámico sin fin nos brinda incluso una "tierra prometida" que, si bien está bastante idealizada, incluye al "conciliador". Es decir, no está libre de contradicciones. ${ }^{12}$ La igualdad con las cosas, por último, con las "camaradas cosas" (544) es, además de un anhelo revolucionario, una transvaloración efectiva no solo de los valores cristianos, sino de toda una concepción occidental de la que abreva Lunacharski.

Porque Iván en el Paraíso, a pesar del grito final de "No hay acuerdo. ¡Viva la revuelta! / No hay culpables. ¡Sólo eterno movimiento!" (59) hace largo tiempo que no se mueve. Primero, porque la negación de la culpa es otro lugar común opuesto, resignificado, pero aún presente como condición de posibilidad del razonamiento. Segundo, porque la cosmovisión del panteísmo trágico no surge como resultante de una orientación mística de la pieza, sino de su punto de vista racional en diálogo con la teología. Ya en su Religión y socialismo (1908), donde defendía la fe del socialismo sin dios como una manera de tener esperanza en el triunfo y darle su afecto a la lucha (libro del que se retracta a posteriori), Lunacharski sostenía que el "socialismo es la lucha organizada de la humanidad contra la Naturaleza para someterla por completo a la razón: en la esperanza de la victoria, en la aspiración y la concentración de las fuerzas está la nueva religión" (Lunacharski, 1908). El esquema de pensamiento es constante. En su disputa de 1925 con Vvedenski, formulará la misma idea de la humanidad contra la Naturaleza parafraseando a Engels: "el paso al comunismo será un salto del reino de la necesidad al reino de la libertad" (Lunacharski, 2012). ${ }^{14} \mathrm{Y}$ volverá a citar a Engels tres años más tarde en su conferencia sobre Chernishevski. Lunacharski quiere anular la necesidad para ser libre, Maiakovski se corre y revoluciona las nociones mismas de trabajo, de bien, de mal, de libertad.

Maiakovski va futuristamente hacia el futuro: su paraíso es una tierra prometida, siempre por delante, el premio del trabajo. Lunacharski avanza retrocediendo hacia un paraíso perdido donde la ciencia hará del trabajo algo innecesario. También difieren los valores a desarrollar. Maiakovski no dejará de luchar contra la burocracia. En La chinche (1929) criticó un socialismo ya alienado por el que se ha vencido a la naturaleza, donde los árboles artificiales dan sus frutos en platos y ya no existe el amor... Lunacharski, a pesar de haber abrazado un ideal menos colectivo y que valora,

12 La tensión entre la idealización y la afirmación de un mundo en el que no hay una armonía final hace que Maiakovski la proyecte en las didascalias del comienzo a un futuro intergaláctico en el que "dentro de cincuenta años, quizás, se lancen al ataque de planetas lejanos los buques aéreos de la comuna" (452).

${ }_{13}$ Cf. López Arriazu (2019b).

14 Originalmente en F. Engels, La revolución de la ciencia de Eugenio Dühring (Anti-Dühring) p.28o. Biblioteca de Autores Socialistas. https://webs.ucm.es/info/bas/es/marx-eng/78ad/78AD.htm 
en la línea marxista clásica, las diferencias individuales, seguirá las vías científicas, identificando cada vez más los desvíos con metáforas de enfermedad, justificando la ingeniería social con metáforas de jardinería. El proyecto de Lunacharski antecede a la revolución. Así había definido la "tarea religiosa del hombre nuevo" en Religión y socialismo: "La reconciliación de las leyes de la vida y las leyes de la naturaleza ocurrirá por medio del triunfo de la vida con ayuda del conocimiento y de la técnica" (Lunacharski, 1908). Pero ya aprendimos a desconfiar de tales reconciliaciones. Maiakovski también comienza a formar su hombre nuevo en el futurismo prerrevolucionario, pero sin dialéctica, con puro devenir. Insolente, carnavalesco y afirmativo, seguirá revolucionario hasta su suicidio. La posición de Lunacharski ganó en su momento recuperando lo perdido. Maiakovski sigue prometiendo. Hoy, a 100 años de Misterio bufo, su hombre nuevo está más nuevo que nunca. 


\section{Q Bibliografía}

»Agamben, G. (2006). Lo abierto. El hombre y el animal. Buenos Aires: Adriana Hidalgo Editora.

»Chaiánov, A. (2011). Путешествие моего брата Алексея в страну крестьянской утопии. En: http://az.lib.ru/c/chajanow_a_w/text_oozo.shtml Renovado el 21-04-11 [Viaje de mi hermano Alexéi al país de la utopía campesina].

》Deleuze, G. (1998). Nietzsche y la filosofía. Barcelona: Anagrama.

" Guevara, E. (1978). El hombre nuevo. Cuadernos de cultura latinoamericana 20. México: UNAM.

»Ivanova, М. V. (2007). “Мистерия-Буфф В. В. Маяковского: Опыт Философской Интерпретации". Вече. Журнал Русской Философии и Культуры. Выпуск 18. Санкт-Петербургский Государственый Университет. Институт Философии http://philosophy.spbu.ru/userfiles/ rusphil/Veche\%20№18-7.pdf ["Misterio bufo de V. V. Maiakovski: Un ensayo de interpretación filosófica”. Veche. Revista de Filosofía Rusa y cultura, Número 18. Universidad Estatal de San Petersburgo. Instituto de Filosofía].

" Jakobson, R. (1977). El caso Maiakovski. Barcelona: Icaria.

» Kojnó, І. Р. (1972). “Уроки одной дискуссии”. En: Наследие А. В. Луначарского. Философия, политика, искусство, просвещение. http:// lunacharsky.newgod.su/issledovania/cherty-portreta/uroki-odnoj-diskussii/ [“Lecciones de una discusión”. En: La herencia de A. V. Lunacharski. Filosofía, política, arte y educación].

»López Arriazu, E. (2019a). “El jugador de Dostoievski”. En Ensayos Eslavos, Buenos Aires: Dedalus Editores.

»López Arriazu, E. (2019b). “Los cisnes rapaces de Platónov”. En Eventos Académicos de la Facultad de Filosofía y Letras de la UBA. http://eventosacademicos.filo.uba.ar/index.php/EIAPA/IEIAPA/paper/view/4385

»López Arriazu, E. (2020) “El Estado y la religión. Nosotros de Zamiátin”. Badebec, Revista del Centro de Estudios y Crítica Literaria, Vol. 19 № 19, Septiembre. https:// revista.badebec.org/index.php/badebec/article/view/469/424

»Lunacharski, A. V. (1918). “Коммунистический спектакль”. En: Наследие А. В. Луначарского. Философия, политика, искусство, просвещение. http://lunacharsky.newgod.su/lib/ss-tom-3/kommunisticeskij-spektakl/ [“Un espectáculo comunista”. En: La herencia de A. V. Lunacharski. Filosofía, política, arte y educación].

"Lunacharski, A. V. (2020). Iván en el Paraíso. En: La Utopía en Rusia. Textos críticos y literarios. Ficha de cátedra. Buenos Aires: OPFyL, UBA. Traducción de E. López Arriazu.

» Lunacharski, A. V. (2012). "Христианство или коммунизм». En: Lib.ru http:// az.lib.ru/l/lunacharskij_a_w/text_1925_hristianstvo_ili_kommuniszm.shtml ["Cristianismo o comunismo"].

»Lunacharski, A. V. (1908). Религия и социализм, том I. En: The charnel-house, https://thecharnelhouse.org/2015/11/о5/анатолий-луначарский-религия-исоциа/ [Religión y socialismo, tomo l. En: The charnel-house]. 
» Murashov, А. (2016). “Новый человек и его дискурс". En: https://discours.io/articles/theory/novyy-chelovek-i-ego-diskurs ["El hombre nuevo y su discurso"].

» Nietzsche, F. (1997). Genealogía de la moral. Madrid: Alianza Editorial.

»Pushkin, S. (2005-2006). Собрание сочинений: в 10 т. Москва: Вагриус. [Obras completas en 10 volúmenes].

"Siniavski, A. (1990). La civilización soviética. México: Editorial Diana.

» Turguéniev, I. С. (1994). Опцы и дети. En: Собрание сочинений. Том пятый. Москва: Русская Книга. [Padres e hijos. En: Obras completas. Tomo quinto. Moscú: El libro ruso].

"Zabelínskaia, O. S. у Novikov, S. G. (2011). “Разработка А. В. Луначарским идеала "Нового человека»: ретроспективный взгляд". En: «Учебный эксперимент и образование», Материалы второй Всероссийской научно-практической конференции с международным участием. http://lunacharsky.newgod.su/issledovania/razrabotka-a-v-lunacharskimideala-novogo-cheloveka/ [ "La reelaboración de A. V. Lunacharski del ideal del "Hombre nuevo": una mirada retrospectiva". En: Experimento científico y educación. Materiales de la segunda conferencia científico-práctica de toda Rusia con participación internacional]. 
